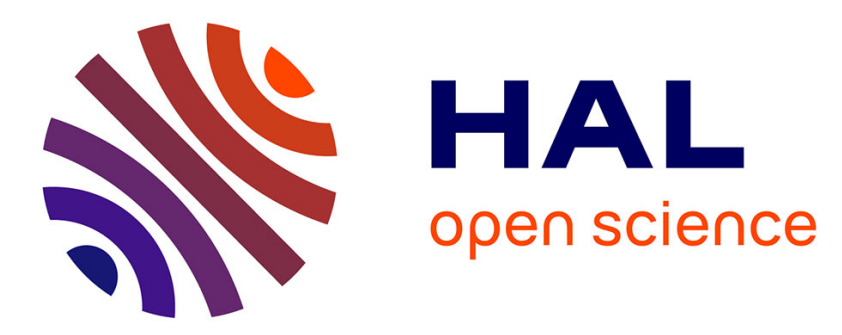

\title{
Game System of Coordination Skills Training for Elderly People
}

Nobumitsu Shikine, Yuki Hayashi, Takeshi Akiba, Mami Tanasaki, Junichi Hoshino

\section{> To cite this version:}

Nobumitsu Shikine, Yuki Hayashi, Takeshi Akiba, Mami Tanasaki, Junichi Hoshino. Game System of Coordination Skills Training for Elderly People. 15th International Conference on Entertainment Computing (ICEC), Sep 2016, Wien, Austria. pp.24-37, 10.1007/978-3-319-46100-7_3 . hal-01640301

\section{HAL Id: hal-01640301 https://hal.inria.fr/hal-01640301}

Submitted on 20 Nov 2017

HAL is a multi-disciplinary open access archive for the deposit and dissemination of scientific research documents, whether they are published or not. The documents may come from teaching and research institutions in France or abroad, or from public or private research centers.
L'archive ouverte pluridisciplinaire HAL, est destinée au dépôt et à la diffusion de documents scientifiques de niveau recherche, publiés ou non, émanant des établissements d'enseignement et de recherche français ou étrangers, des laboratoires publics ou privés.

\section{(c)(1)}

Distributed under a Creative Commons Attribution| 4.0 International License 


\title{
Game System of Coordination Skills Training for Elderly People
}

\author{
Nobumitsu Shikine, Yuki Hayashi, Takeshi Akiba, Mami Tanasaki, Junichi Hoshino \\ University of Tsukuba, Graduate School of Integrative and Global Majors, Tsukuba, Japan \\ \{shikine-shikine, yuki-hayashi \} dentcomp.esys.tsukuba.ac.jp \\ \{t.akiba,m.tanasaki\}@sic-tky.com \\ jhoshinod esys.tsukuba.ac.jp
}

\begin{abstract}
In this paper, we propose upper-limb-grasp motion as coordinated movement of five fingers and upper limbs. This coordination skill is important of daily living and we use unconscious. We divide upper-limb-grasp motion into 6 motion elements game system analysis and visualize with upper-limb-grasp motion measurement controller and game contents. We compared elderly and younger people and consider the result. As the result, we research exercise menu and game contents, technique of visualization.
\end{abstract}

Keywords: elderly people, coordinated movement, upper-limb-grasp motion, training, game system

\section{Introduction}

In our daily lives, actions such as holding objects, opening doors, reaching for things from high places, cooking, driving a car, and other various activities are carried out by moving the upper-limbs and fingers based on visual information. However, it is known that our faculty to carry out these cooperative motions decreases with age[1]. Therefore, there is a need for older people to train the cooperative motions between the arms and fingers. This has become a particularly important issue as the populations of Japan, and other developed nations, begin to age [2].

In the scope of cooperative motion between the arms and fingers, it is has been found after measurements were carried out that focussed on the adjustment of strength in the fingers, there is a decrease in function with age [3], and training is carried out to focus on dexterity[4]. There are also limitations on arm movements, and a measurement of physical function using an actuator and training are performed[5]. The motion algorithm of hand-eye coordination is also being researched [6].Furthermore, it has been made clear that training carried out through a game designed to improve cognitive function can also help improve the multitasking capabilities necessary for cooperative motion even in the elderly [7]. However, while there is a need to break down and investigate each aspect of physical movement for the arms and fingers so that the cooperative motion between the two can be trained, as well as for an analysis of how they move cooperatively, this is no easy task. Therefore, it's very difficult to develop a system that trains for cooperation between them.

adfa, p. 1, 2011.

(C) Springer-Verlag Berlin Heidelberg 2011 
This paper defines the cooperative motion of the upper-limbs and fingers based on visual information as upper-limb grasp motion. And propose a game system to support training with a dumbbell-shaped controller, which is easy to grasp with both hands and game contents. We examined the movements that make up the cooperative motions between the upper-limbs and fingers, did an analysis and visualization for elderly people. And through it we support the implementation of healthy exercise and the selfawareness of motion characteristics for upper-limb grasp motion training.

By breaking down the elements that make up upper-limb grasp motions into 6 items; the pressure and balance of the fingers, the exercise capabilities of each finger, the smoothness of upper-limb movement, mobility range of the shoulders, cooperation between the upper-limbs and fingers, and the coordination of both hands, changes in the physical capabilities are analyzed.

In order to evaluate the effectiveness of this system, the upper-limb grasp motion of the elderly will be measured, and by comparing the analyzed results with a younger age range, the change in physical capabilities with age will be investigated, and the performance indicators and visualization method examined.Furthermore, the giving of visual feedback either to the user or care manager about their motion characteristics and how they stand physically compared to other users is useful in the promotion of healthy exercise, an increase in attentiveness to their daily activities, and the creation of a longterm training care plan.

\section{Previous studies}

\subsection{Decline in physical capabilities with age}

Through the results of the Jebsen-Taylor hand function test, which investigates the correlation between finger function and ageing, it is known that finger function begins to decline from the age of 60 [8]. In the research that focuses on function in the fingertips, such as pinch strength and accuracy, it was suggested that pinch strength declines with age and it becomes more difficult to keep hands still due to a loss of feeling in the fingertips [9], which leads to a drop in accuracy [10][11].

Though it is a recognized fact that motor function declines with age, it's also reported that there are individual and crosswise differences [13], and that as there are also differences in the tendency towards this decline, it is important to take precautions to prevent it [12]. In addition to this, upon suggesting that motor function declines with age, it was also stated that there is also a scope for improvement [14].

\subsection{Research concerning upper-limb and finger coordination}

In hand-eye coordination research, the movement of the eye and the upper-limbs when pointing to a dot was analyzed [6]. The result of this research was that it showed that the method of pointing is powered by feed-forward control.

Hand and upper-limb rehabilitation is effective in stroke rehabilitation and attempts are being made to restore physical faculties [15]. Many methods are proposed, including both-side training, one-sided training, and rhythm training. 


\subsection{Game systems that improve physical and cognitive function}

In the game Neuro Racer [7], cognitive function is shown to improve as the user has to push buttons at the correct time while racing, forcing them to do multiple actions at once. However, as this game only focuses on multitasking, the amount of motor function that the user is using is limited.

Games are also now being brought out onto the market that have been developed specifically to improve physical faculties and cognitive function. The standing up game "Rehabilium Kiritsukun", which is often used in stroke treatment, and is based on everyday movements, has also made its way onto the market [16]. As the user goes through the game making standing movements they can observe their form on the screen and carry out training of this function. In addition to this, there is a piece of equipment called the "digital mirror" that allows them to see their own physical functionality as they make certain movements. Through imitating the instructors movements while checking their form in a screen that forms a half-mirror and a set of balance scales on the floor, effective rehabilitation can be carried out.

\subsection{Analysis of movements and cognitive function in the elderly}

In research that studies the reaching movements of hemiplegia patients, a chronological data analysis is carried out, as well as an RMS and autocorrelation linear study, and a non-linear analysis that assumes dimensionality reduction through minimizing nearest-neighbor error[17]. A significant correlation with the clinical rating scale can be seen and as a rating scale it shows useful things. Furthermore, muscle potential is also used to analyze arm movement. In research that measured muscle potential by asking participants to perform simple movements, such as rotating a rod that they were grasping by $90^{\circ}$, there was a scattering in results [18].

As a performance indicator for the smoothness of movement, a minimum-jerk model is proposed to work as a rating scale for the sum total of the multiplication of jerks [19]. This model proved useful for evaluating stability in an experiment that looked at the stability of the walk of an elderly person to examine the smoothness of movement [20]. In regards to simple rotation of the arm, in research that looked in detail at the greatest angle the arm could reach, its speed, and its acceleration, it was found that there was little difference between elderly and young people when they were asked to rotate their arms at a slow speed of their choice, but the difference got much greater as they were asked to speed up.

Furthermore, when the dual-tasking ability of posture and attentiveness was investigated over 4 poses, it was found that the older someone was, the more difficult it was for them to hold their attentiveness as they held complicated poses.

Cognitive function is also analyzed, and analyses concerning fingertip movement and the relationship between motor capabilities and cognitive function were carried out by using fMRI and EEG.

Although research that aims to improve physical and cognitive function in the elderly like that above, which has been conducted from a variety of viewpoints, is being carried out, there is still no analysis or visualization that focuses on the cooperative motions between the fingers and upper-limbs or support for long-term training. This document proposes a system that covers these functions. 


\section{System summary}

\subsection{Upper-limb grasp motion}

In this document, even within the scope of visiomotor coordination, upper-limb grasp motion refers to the coordinated movements between vision and the fingers and upperlimbs. We have sorted the physical elements of upper-limb grasp motion into 6 types, the details of which are explained below:

1. Balance of finger pressure

This is the deviation of the maximum grip strength in each finger when gripping an object using all fingers on both hands. It's known that when elderly people put force on various parts of an object at the same time, that force is less then when they put that force on a more restricted area. A bilateral deficit is also reported. In this paper, because the pressure sensor of the controller has constant area, the physical quantity we measured by fingers is force $[\mathrm{N}]$.

2. Finger exercise capacity

This is related to the ability to join together and move all of the fingers on both hands. It is the ability to move the intended finger at the intended timing, in the intended way. In everyday life people don't only grasp things, sometimes they often need to power 2 fingers to make a pinching motion, or a specific fingers to cook, or even specific fingers in order to operate machines. It's reported that the strength and accuracy of the fingers declines with age [9][10][11].

3. Upper-limb exercise smoothness

This is when an upper-limb is moved at a fixed speed, and concerns the fragmentation that occurs if this movement is not smooth. It's reported that for elderly people, if it's very difficult for them to demonstrate a constant speed which reduces the smoothness of their exercise.Acceleration and jerks [19] are often used as performance indicators for smoothness.

4. Shoulder movement scope

This is an element of movement that focuses on the shoulder and the scope in which it can be rotated up, down, left, or right. It's said that the range in which the shoulder can be moved upwards decreases with age. Movable region measurement is carried out in physiotherapy, and the exercise direction that will be examined in this research is the bend of the shoulders (and shoulder girdle) as well as their inner and outer rotations.

5. Upper-limb and finger coordination

This is an essential element of movement when moving the fingers and an upperlimb at the same time, and is related to the movement of gripping something as it is moved. It is the ability of how accurately and how far the hand can go as it grips an object and is moved by joints such as the elbow and shoulder. When a person ages, their movements become slow, and accuracy also decreases. This element of movement is usually examined using the pegboard test.

6. Hand-eye coordination

This relates to the movement carried out by confirming the position of an object through sight and moving hand accurately and at the intended timing to grasp it, and also to grasp objects that are in motion. Adjustment of the position of the hands encompasses both feed-forward control and feed-back control. Feed-forward control is required for actions such as catching a ball that is flying towards you, while feed-back 
control is required when adjusting the angle of the hand to prevent a glass of water from spilling as it is carried.

\subsection{Exercise support system summary}

The images of the game system that measures, analyzes, and visualizes the upperlimb grasp motion of elderly people in use are shown in Fig.1. The user sits in a chair, grasps the controller that will measure the upper-limb grasp motion, and proceeds through the game content that is displayed on the screen. The exercise process is explained by a character in the game who acts as an instructor. The game analyzes the characteristics of each user's upper-limb grasp motion, and gives feedback to either the user or their care manager.

The upper-limb grasp motion is analyzed and visualized and supports the comprehension of the gap in capabilities in the upper-limb grasp motion of the elderly and the young. It measures the motion characteristics found in upper-limb grasp motion in all users, including the young, and by updating the performance indicators, can check the user's motion type, as well as make clear its relation to the state of their health.

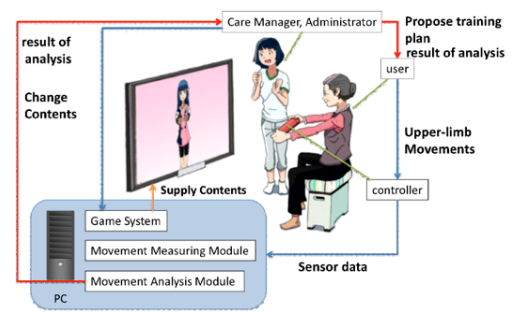

Fig. 1. System Image

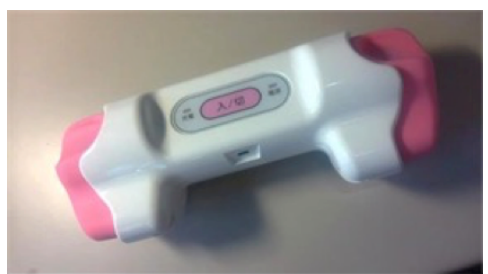

Fig. 2. Upper-limb-grasp motion measurement Controller (System Instruments Co.,Ltd.)

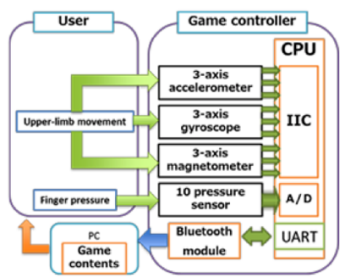

Fig. 3. Block diagram

\subsection{A controller that measures upper-limb grasp motion}

In order to be able to measure finger pressure, upper-limb movement, or upper-limb grasp motion, which is a combination of the two, it's necessary to be able to measure each finger's pressure and the movement of the arm. In this document, we have developed a controller like that in Fig. 2 together with System Instruments Ltd. The area where the controller is grasped has a rubber cover, and it's shaped to fit all 5 fingers. The pressure sensors buried into the area where the controller is gripped measures finger pressure $[\mathrm{N}]$, and upper-limb movement is calculated by 3 -axis internal sensors 
that measure acceleration $\left[\mathrm{m} / \mathrm{s}^{2}\right]$, angular velocity $[\mathrm{rad} / \mathrm{s}]$, and geomagnetism. Using the body as a center point, the position of the user's up, down, left, and right arm rotations is calculated by information from the acceleration and angular velocity sensors. The data from each sensor is sent to computer via Bluetooth, where it is stored, calculated, and reflected on the screen (Fig. 3).

The values from the sensors are converted by this formula (1)(2)(3)(4)in to the rotational angle (roll, pitch, yaw) [deg] of the arm using the shoulder as a center point. The roll and pitch directions use the acceleration value. For the yaw direction, the value of the angular velocity sensor is integrated to estimate the current position, and for this reason the game needs to be calibrated before the game content starts.

$$
\begin{aligned}
& \theta_{\mathrm{r}} \fallingdotseq \mathrm{c}_{\mathrm{r}} a_{x} \\
& \theta_{\mathrm{p}} \fallingdotseq \mathrm{c}_{\mathrm{p}} a_{y} \quad \mid c_{\mathrm{p}}>a_{y} \\
& \theta_{\mathrm{p}} \fallingdotseq \mathrm{c}_{\mathrm{p}} a_{z} \quad \mid c_{\mathrm{p}} \leq a_{y} \\
& \theta_{\mathrm{r}} \fallingdotseq \mathrm{c}_{\mathrm{y}} \int\left(g_{x}(t) \cos \theta_{\mathrm{r}}-g_{y}(t) \sin \theta_{\mathrm{p}} \cos \theta_{\mathrm{r}}-g_{z}(t) \cos \theta_{\mathrm{p}} \cos \theta_{\mathrm{r}}\right) d t \\
& \left.a_{x}, a_{y}, a_{z}: \text { triaxial acceleration }\left[\mathrm{m} / \mathrm{s}^{2}\right], \quad g_{x}, g_{y}, g_{z}: \text { triaxial angular velocity[rad } / \mathrm{s}\right] \\
& \theta_{\mathrm{r}}, \theta_{\mathrm{p}}, \theta_{\mathrm{y}}: \text { posture (roll, pitch, yaw) [deg], } \quad c_{\mathrm{r}}, \mathrm{c}_{\mathrm{p}}, \mathrm{c}_{\mathrm{y}}: \text { proportionality constant }
\end{aligned}
$$

\section{Configuration of the game unit}

\subsection{Game unit overview}

A game unit is created to measure upper-limb grasp motion, and each game unit is used to acquire data concerning each element of movement related to upper-limb grasp motion. Each game unit features a character who acts as an instructor, re-enacting all of the movements that the user performs, and encourages the appropriate exercise via voice instruction. Furthermore, the user can see the state of their movements through the controller and interface displayed within the game (Fig. 4). The controller is displayed on screen in relation to its actual location. Finger pressure is displayed by lighting up the area around the name of the respondent finger in red.6 types of game content come with the unit, each corresponding to one of the 6 elements of movement or a combination thereof. Since the movements of the user can be analyzed in each section, a performance value can be calculated for each element of movement.

\subsection{Content and traits of each game unit (a)(b)(c)(d)(e)(f)}

(a) Movement imitation game (Fig. 4.a)

The upper-limbs are moved to imitate the movements directed by the instructor. The aim of the game is to move the arm up, down, left, right, and in a diagonal direction using the shoulder as a center point (Fig. 5). The game last for 5 minutes and examines upper-limb exercise smoothness, shoulder movement scope, and flexibility.

(b) Simultaneous maximum finger pressure game (Fig. 4.b)

The controller is grasped using all 5 fingers on each hand, and the maximum finger pressure for each is calculated. The measurement is taken twice to imitate a real finger pressure examination. This examines the balance of finger pressure. 
(c) Finger reaction game (Fig. 4.c)

The screen indicates one finger from both of the users hands, which they must then press down as fast as they can. The time between the direction being given and the finger being pressed is then measured. This game examines finger exercise capacity. (d) Object moving game (Fig. 4.d)

This game compels the user to pick up an object in the game and move it to the specified location. The main element of movement that is examined here is upper-limb and finger coordination. The in-game catcher is moved by either rotating the arm in a pitch or yaw direction and closing in upon the object. When the catcher is close to the object, it can be grasped by applying pressure that totals a value greater than that already fixed. The movement to transfer the object to the designated area is performed 3 times from left to right, and 3 times from right to left. The amount of time taken to complete the task and the number of times the object has been dropped are then calculated.

(e) Catch ball game (Fig. 4.e)

The user catches the ball that is flying towards them 3 times within the game. The position of where the ball will land is fixed, and it always comes towards the user in the game. This game examines hand-eye coordination and feed-forward control capability is necessary for getting the grasp timing right. The amount of time between the users catch timing and an accurate timing is measured.

(f) Ball rolling game (Fig. 4.f)

The controller is tilted backward and forwards and from left to right to cause the ingame ball to roll towards the target area. This game is repeated 3 times, and the ball starts at a different position each turn. This game examines hand-eye coordination as it requires the user to use the visual information in front of them to alter the direction of the ball and the ability of feed-forward control so the user knows when to tilt the controller. The game measures how long it takes the user to get the ball to the target area.

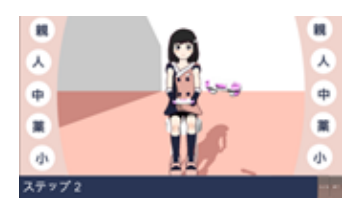

(a) Imitation movement

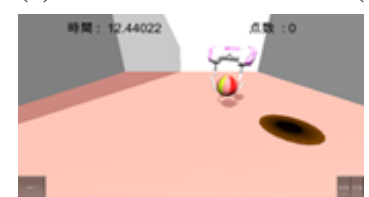

(d) Move the ball

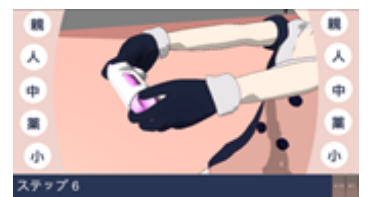

(b) Max pressure of all finger

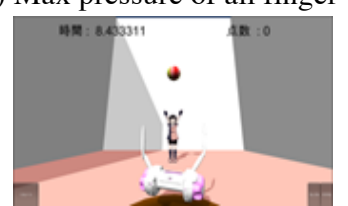

(e) Catch the ball

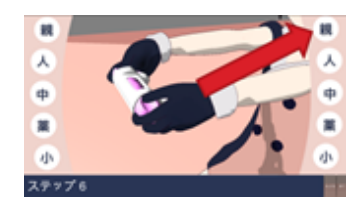

(c)Reaction of finger

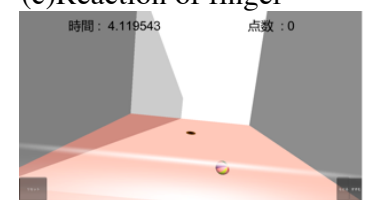

(f) Tilt ball game

Fig.4.Game contents base vision

\section{$5 \quad$ Analysis and Visualization of upper-limb grasp motion}

\subsection{Motion analysis}


An analysis is carried out on the data measured by the games and the performance values for the elements of movement calculated. To visualize the parameters for each element of movement, they are put into 5 levels of evaluation. The method for the analysis is shown below:

\section{Balance of finger pressure}

Studies the scattering in maximum pressure from each finger when the user puts pressure on all fingers in the simultaneous maximum pressure finger examination game (b), and standard deviation is calculated from the average pressure of each finger (5). The value of the standard deviation is then evaluated into one of 5 levels.

$$
\begin{gathered}
\sigma=\sqrt{\frac{1}{10} \sum_{i=1}^{10}\left(F_{i}-\mu\right)^{2}} \\
\sigma: \text { Standard deviation } \\
F_{1} \sim F_{10}: \text { each finger pressure }\left(F_{1} \text { is right thumb, } F_{10} \text { is left pinkie) }[\mathrm{N}]\right. \\
\mu: \text { The mean value of each fingers' maximum pressure }[\mathrm{N}]
\end{gathered}
$$

\section{Finger exercise capacity}

In order to investigate whether the user can move each finger as instructed in the finger reaction game (c), the amount of time taken between the direction being given and the maximum finger pressure for the relevant finger being exerted is evaluated into one of 5 levels.

\section{Upper-limb exercise smoothness}

In order to study the smoothness of the arm movements when the shoulder is centered during the movement imitation game (a), the minimum jerk model is calculated from the value of the 3-axis acceleration sensor. The evaluation function value is then evaluated into one of 5 levels.

$$
\begin{aligned}
C= & \frac{1}{2} \int_{0}^{t_{f}}\left\{\left(a_{x}(t)\right)^{2}+\left(a_{y}(t)\right)^{2}+\left(a_{z}(t)\right)^{2}\right\} d t\left[\mathrm{~m} / \mathrm{s}^{3}\right](6) \\
& a_{x}, a_{y}, a_{z}: \text { triaxial acceleration }\left[\mathrm{m} / \mathrm{s}^{2}\right]
\end{aligned}
$$

4. Shoulder movement scope

To study the flexibility and range of movement when the arm is rotated with the shoulder centered during the movement imitation game (a), the amount that the controller was moved either up, down, left, right, or at a slant from its place on the knees is evaluated. The evaluation is based on the reference angle of the outer rotation of the joint movement region measurement, and evaluated into one of 5 levels. A value is calculated from the average of each direction.

\section{Upper-limb and finger coordination}

To study hand-eye coordination in the object moving game (d), the amount of time taken to move the ball and the number of times that it is dropped is evaluated. The time required is evaluated into one of 5 levels, and a level is dropped for each time the ball was dropped.

\section{Hand-eye coordination}

In order to study feed-back control capabilities within the scope of hand-eye coordination during the ball rolling game (f), the time taken to roll the ball to the target area is evaluated into one of 5 levels. 


\subsection{Supporting training by visualization}

So that each user can easily comprehend the characteristics of their elements of movement, their data is made into an easy-to-understand spider chart (Fig. 5). The average data for each generation and for young people can also be displayed, making it easier for the user to see where they stand when compared to others.

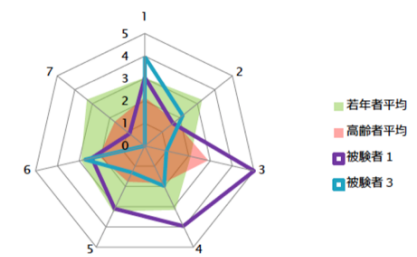

Fig.5. Upper-limb-grasp motion cobweb chart

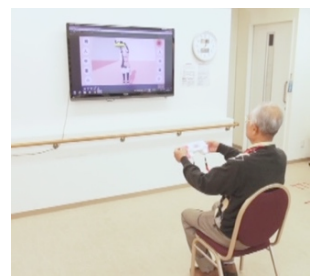

Fig.6. Experimental situation

\section{Evaluation experiment}

\subsection{Experiment}

To test the effectiveness of the measurement of upper-limb grasp motion, analysis, and visualization of results using the created system, a comparison was carried out between the elderly and the young.

\subsection{Target group}

The research content was explained orally and through literature to the target group, and 12 healthy young and elderly people who gave their consent were selected. The elderly group was made up of 6 people ( 3 men and 3 women with an average age of $79.3 \pm 5.7)$ who weren't prevented from exercising by their doctors, and the younger group was also made up of 6 people ( 3 men and 3 women with an average age of $24.3 \pm 2.7$ ) who were healthy university students.

\subsection{Method}

The content of the game was displayed on a large screen via PC, and the target group took part in the experiment by taking the controller and sitting in a chair $2 \mathrm{~m}$ away from the display. (Fig.6) The way to use the controller was explained. The games played were the 6 that were described in Chapter 4 . The elements of movement of both the younger and older group were measured using the controller and game content, and an evaluation was calculated relating to each of the 6 types of motion characteristics.

\subsection{Results}

The evaluation value of each of the 6 types of motion characteristics were calculated, and the average values of the men and women from the older group, and the men and women of the younger group are shown in Fig. 7.

In all characteristics with the exception of the upper-limb exercise smoothness, the averages of both the men and women in the younger group yielded better results than 
the averages of the men and women in the older group. However, in the inspection analysis, it was found that the only trait that showed a significant gap was the finger exercise capacity $(\mathrm{p}<0.05)$ (Table 1$)$. It was found that when the reaction time was compared for each finger(Fig. 8), the younger group had better results in every finger than the older group.

Furthermore, when each trait was analyzed in detail, a significant difference $(\mathrm{p}<0.05)$ between the older and younger group was found in the flexibility and movement scope of the shoulder in the up and down direction only.

\section{$7 \quad$ Investigations}

We analyzed by quantifying 6 motion elements composing upper-limb movement. Although every subject's result was different from each other, elderly people group's result was more varied than younger group. So that we found, even they are same generation, elderly people's exercise capability and characteristic are not the same for each person. The only trait which showed a significant difference was the finger exercise capability component, it's thought that this is because there is a big scattering in the capabilities of those in the older group.

Table 1 The comparison of the mean value of each parameter of upper-limb coordination

\begin{tabular}{|l|l|l|l|}
\hline & elderly & young & P value \\
\hline balance of finger pressure $[\mathrm{N}]$ & 212.693 & 186.952 & 0.3967 \\
\hline finger exercise capacity $[\mathrm{s}]$ & 1.808 & 1.210 & 0.0145 \\
\hline upper-limb exercise smoothness $\left[\mathrm{m} / \mathrm{s}^{3}\right]$ & 14003893 & 17854048 & 0.38517 \\
\hline shoulder movable scope $[\mathrm{deg}]$ & 91.783 & 73.268 & 0.09963 \\
\hline upper-limb-finger coordination $[\mathrm{s}]$ & 25.815 & 6.1230 & 0.05929 \\
\hline eye-hand coordination $[\mathrm{s}]$ & 54.775 & 15.260 & 0.15183 \\
\hline
\end{tabular}

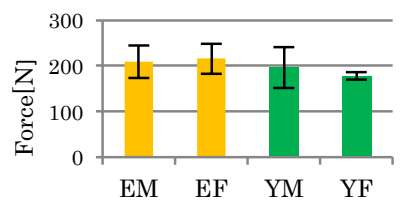

1. balance of finger pressure

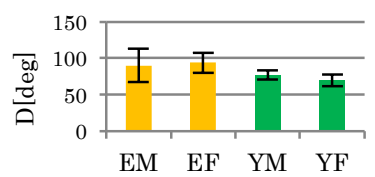

4. shoulder movable scope

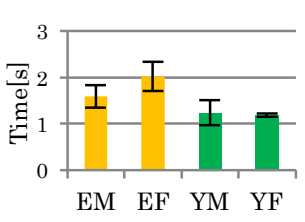

2. finger exercise capacity

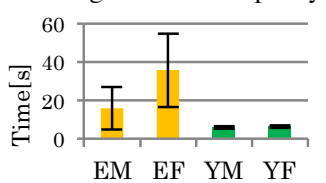

5. upper-limb-finger coordination

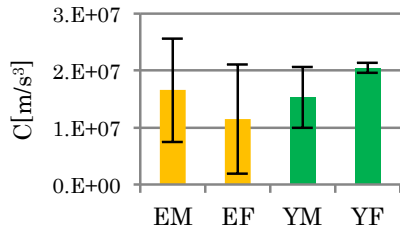

3. upper-limb exercise smoothness

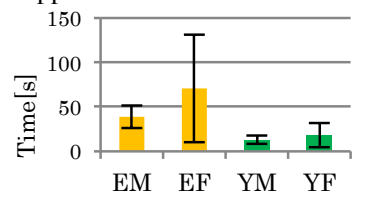

6. eye-hand coordination

Fig.7. The comparison of upper-limb coordination EM(elderly male), EF(elderly female), YM(young male), YF(young female) 

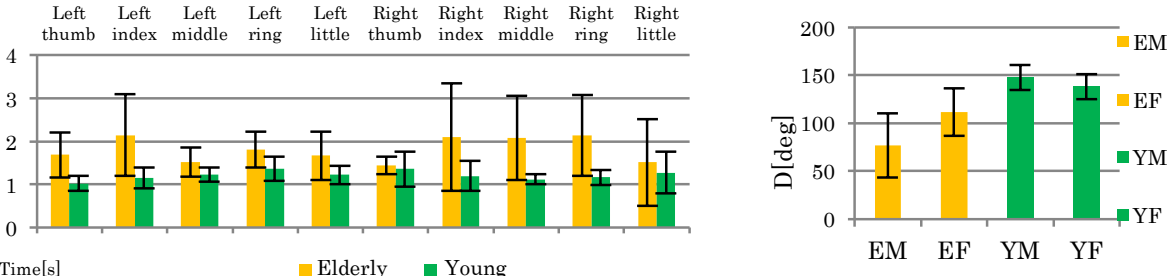

Fig.8. finger exercise capacity Fig.9. shoulder movable scope(up-down)

Furthermore, in relation to the finger exercise capability characteristic, which showed a significant difference, although it's thought that the older group's delay in reaction speed is also part of the cause, it's also thought that due to the larger disparity of results when compared to the younger group, the older group find it difficult to move their finger by their reflexes (Fig. 8). In fact, during the experiment itself, it was observed that the older group would move their fingers after vocalizing the direction, or move the wrong finger by mistake. It could be thought that the older group need to comprehend which finger to move and then move the finger after thinking about it. Therefore, there's a possibility that it's difficult for them to move their fingers intuitively in their private lives. (e.g. using a remote control, chop stick, scissors)

Though in this paper we didn't impression evaluation, elderly who use our system said "Interesting" "I want to continue to use" "I want to buy". It seems that we can urge to do training by giving a game system entertainment.

\section{Conclusion}

This paper has focused on the cooperative motion between the fingers and upperlimbs, a movement important to everyday life, and defined it as the upper-limb grasp motion. The components of this motion were broken down into 6 elements, and a game controller and contents that could measure each element of movement created, as well as a games system that evaluated and comparatively analyzed this data before visualizing it. To evaluate this system, the upper-limb grasp motion of a group of older people and a group of younger people was measured, analyzed, a comparison performed, and visualized before an examination of the performance indicators was also undertaken.

As for the results, we found elderly people's exercise capability and characteristic are not the same for each person compared from younger people. As significant differences could not be found in all of the elements of motion that comprise the upperlimb grasp motion between the older and younger groups, the experiment did not progress to the visualization stage or the examination of the performance indicators. However, from the larger disparity found in the measured values in each element of movement in the older group when compared to the younger group, it was found that there is an individual gap between upper-limb grasp motion capabilities that bears no relation to age. Furthermore, it was also found that in the finger exercise capability tests, the difference in movement when compared to the young people, as well as the measurement results themselves, was significant. 
But considering that elderly people's exercise capability and characteristic are not the same for each person, it is still difficult to examine generally exercise characteristic of elderly. It is necessary to collect more data from subjects. And to define more suitable performance index which divides elderly from younger by that is our future work.

In the future it will have found, elderly people and care managers can make it easier to see their characteristic or where they stand when compared to others by using this system. Furthermore, it can be expected that this system will be useful for the people who makes long-term care plan.

\section{References}

1. Rachael D.Seidler.: Motor control and aging: links to age-related brain structural, functional, and bichemical effects, Neuroscience \& Biobehavioral Reviews,34(5):721-733 (2010)

2. 文部科学省: 生涯にわたる心身の健康の保持増進のための今後の健康に関する教育及びス ポーツの振興の在り方について保健体育審議会 答申)

http://www.mext.go.jp/b_menu/shingi/old_chukyo/old_hoken_index/tous hin/1314691.htm

3. Jae Kun Shim: Age-related changes in finger coordination in static prehension tasks, Journal of

4. Applied PhysiologyPublished, Vol. 97, no. 1, 213-224 (2004)

5. Vinoth K.Ranganathan: Skilled Finger Movement Exercise Improves Hand Function, Journal of

6. Gerontology: MEDICAL SCIENCES, Vol.56A,No.8,M518-M522 (2011)

7. Albert C. Lo: Robot-Assisted Therapy for Long-Term Upper-Limb Impairment after Stroke, The

8. New ENGLAND JOURNAL of MEDICINE, 362:1772-1783 (2010)

9. J. D. Crawford: Spatial Transformations for Eye-Hand Coordination, Journal of Neurophysiology, Vol. 92 no.1, 10-19 (2004)

10. J.A.anguera: Video game training enhances cognitive control in older adults (NeuroRacer), NATURE, VOL 501, 97 (2013)

11. Hackel ME: Changes in hand function in the aging adult as determined by the Jebsen Test of Hand Function., Physical Therapy.;72:373-377 (1992)

12. Vinoth K.Ranganathan MSE: Effects of Aging on Hand Function, Journal of the American Geriatrics Society Volume 49, Issue 11, pages 1478-1484 (2001)

13. Caroline J. Ketcham: Age-Related Kinematic Differences as Influenced by Task Difficulty, Target Size, and Movement Amplitude, Journal of Gerontology: PSYCHOLOGICAL SCIENCES Vol. 57B, No. 1, P54-P64 (2002)

14. Julie Bernhardt: Accuracy of Observational Kinematic Assessment of Upper-Limb Movements, PHYSCAL THERAPY, 78:259-270 (1998)

15. Johanne Desrosiersa: Age-related changes in upper extremity performance of elderly people: A longitudinal study, Experimental Gerontology Volume 34, Issue 3, Pages 393-405 (1999)

16. Brach Poston: Movement structure in young and elderly adults during goal-directed movements of the left and right arm, Brain and Cognition 69, 30-38 (2009)

17. Claudia Voelcker-Rehage: Motor-skill learning in older adults - a review of studies on age-related differences, Frontiers in Human Neuroscience:Volume5:Article 26 (2011)

18. Peter G Levine: Stronger After Stroke, Published by Demos Medical Pub (2008)

19. メディカ出版: リハビリウム起立くん http://www2.medica.co.jp/topcontents/kirithu/

20. 矢島大輔: 時系列データ解析による脳血管障害患者のリーチ動作の運動解析, 理学療法科 学 23 (6) 765-772 (2008)

21. W. G. DARLING: Control of Simple Arm Movements in Elderly Humans, Neurobiology of Aging, Vol. 10,pp. 149-157 (1989)

22. J. D. COOKE: Kinematics of Arm Movements in Elderly Humans, Neurobiology of Aging, Vol. 10, pp. 159-165 (1989)

23. TAMAR FLASH , NEVILLE HOGAN: The Coordination of Arm Movements: An Experimentally Confirmed Mathematical Model, The Journal of Neuroscience Vol. 5, No 7. pp. 1688-1703 (1985) 